\title{
MesoTIPS: Combined Approach for the Treatment of Portal Hypertension Secondary to Portal Vein Thrombosis - A Brief Report
}

\begin{abstract}
Introduction: We describe a technique we call "Meso-transjugular intrahepatic portosystemic shunt (MTIPS)" for relief of portal hypertension secondary to portal vein thrombosis (PVT) using combined surgical and endovascular technique. Materials and Methods: Nine adult patients with PVT underwent transjugular intrahepatic portosystemic shunt through a combined transjugular and mesenteric approach (MTIPS), in which a peripheral mesenteric vein was exposed through a minilaparotomy approach. The right hepatic vein was accessed through a transjugular approach. Mechanical thrombectomy, thrombolysis, and angioplasty were performed when feasible to clear PVT. Results: All patients had technically successful procedures. Patients were followed up for a mean time of 13.3 months (range: 8 days to 3 years). All patients are still alive and asymptomatic. Conclusion: We conclude that MTIPS is effective for the relief of portal hypertension secondary to PVT.
\end{abstract}

Keywords: Meso-transjugular intrahepatic portosystemic shunt, portal hypertension, portal vein thrombosis, transjugular intrahepatic portosystemic shunt

\section{Introduction}

Portal vein thrombosis (PVT) is an uncommon condition characterized by blockage or narrowing of the portal vein by intraluminal clot. It occurs mainly in cirrhotic patients $(0.6 \%-34 \%)$ but also in many other conditions, such as hypercoagulable state, inflammatory processes, or mechanical manipulation of the portal vein. ${ }^{[1]}$ Obstruction of the portal vein increases pressure in the more peripheral portal and mesenteric veins resulting in portal hypertension, splenomegaly, ascites, esophageal, and gastric varices. ${ }^{[2]}$ Categories of portal hypertension are prehepatic, intrahepatic, suprahepatic, and hyperdynamic based on the site of obstruction to flow. ${ }^{[3]}$

The clinical presentation of PVT depends on the acuity and extent of the thrombus. It may be asymptomatic however may be as serious as severe variceal bleeding. The symptoms depend mostly on the degree of portal hypertension, regional lymph flow (in the setting of ascites), and collateral formation. In extreme cases, paralytic ileus, shock from variceal bleeding, and mesenteric infarction have been reported. ${ }^{[4]}$

This is an open access article distributed under the terms of the Creative Commons Attribution-NonCommercial-ShareAlike 3.0 License, which allows others to remix, tweak, and build upon the work non-commercially, as long as the author is credited and the new creations are licensed under the identical terms.

For reprints contact: reprints@medknow.com
Controversy exists over the treatment of PVT and its complications. Bilbao et al. describe the use of percutaneous portal vein a transjugular intrahepatic portosystemic shunt (TIPS) as an effective therapeutic alternative in noncirrhotic patients with symptomatic portal hypertension secondary to chronic portal thrombosis. ${ }^{[1]}$

This retrospective study describes a series describing the relief of portal hypertension secondary to PVT with combined surgical and endovascular technique.

\section{Materials and Methods}

\section{Patients' characteristics}

Between June 2000 and April 2007, 9 patients ( 2 women, 7 men), with a mean age of $48.5 \pm 13.3$ years presenting with PVT (4 acute and 5 chronic) underwent consecutive Meso-TIPS (MTIPS) procedures in two major medical centers. Five patients had PVT extending into the superior mesenteric vein (SMV) and 3 into the splenic vein. The presenting symptoms were severe abdominal pain in 5 patients, intractable ascites in 1 patient who had a failed conventional TIPS procedure,

How to cite this article: Chamsuddin A, Nazzal L, Heffron T, Gaber O, Achou R, Martin LG. MesoTIPS: Combined approach for the treatment of portal hypertension secondary to portal vein thrombosis A brief report. Arab J Intervent Radiol 2017;1:20-6. recanalization techniques in association with

\section{Abbas Chamsuddin, Lama Nazzal ${ }^{1}$, Thomas Heffron², Osama Gaber ${ }^{3}$, Raja Achou, Louis G. Martin ${ }^{4}$}

Department of Radiology, Saint George Hospital University Medical Center, Beirut, Lebanon, 'Department of Nephrology, New York University Medical Center, New York, ${ }^{2}$ The Porter Center for Liver Care, Denver, Colorado, ${ }^{3}$ Department of Surgery, Houston Methodist Medical Center, Weill Cornell Medical College, Houston, $T X,{ }^{4}$ Department of Radiology, Emory University Hospital, Atlanta, GA, USA

Address for correspondence: Dr. Abbas Chamsuddin, Piedmont Newton Medical Center, 1526 Hospital Dr NE, Covington, GA 30014, USA. E-mail: achamsuddin@yahoo. com

Access this article online Website: www.arabjir.com

Quick Response Code:

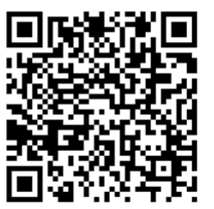


small bowel loop necrosis in 1 patient, bleeding fundal gastric varices in 1 patient, and gastroesophageal variceal in another [Table 1]. In all patients, PVT extended to the intrahepatic PV branches. Three patients had noncirrhotic livers. This retrospective study was approved by the Institutional Review Boards (IRBs) of both participating centers, for which the IRBs granted a waiver of consent. In addition, all regulations of the Health Insurance Portability and Accountability Act of 1996 were followed.

\section{Technical aspects}

In all patients, the procedure was done under general anesthesia. All procedures were performed in the operating room with the endovascular portion performed using a portable digital C-arm, GE-OEC 9800 (GE Healthcare, USA) at both centers. Procedures were initiated by the surgical team performing a transverse infraumbilical incision and exposure of the small bowel. A loop of small bowel was exposed by the surgical team through the laparotomy incision. A small peripheral mesenteric vein was isolated, ligated on the mesenteric side of the bowel, and punctured proximal to the ligation using a micropuncture needle (AngioDynamics, Mini Stick MAX 0.018" Coaxial Microintroducer Kit, Latham, NY, USA). A vein in the distribution of the SMV was preferentially chosen using right-sided bowel loops. A 0.018-inch microwire was advanced through the needle which was exchanged for a 5-Fr coaxial microcatheter. Then, a 0.035-inch angled guidewire (Glidewire ${ }^{\circledR}$ Hydrophilic Coated Guidewire, Terumo Medical Corporation, Somerset, NJ, USA) was advanced through the microcatheter with the placement of a 5 or 6-Fr sheath (Terumo Medical Corporation, Somerset, NJ, USA). The sheath was used to obtain the initial superior mesenteric venogram/portogram, and anatomy assessed [Figures 1-3]. Using a Stiff Shaft angled Glidewire $^{\circledR} \quad$ (Glidewire $^{\circledR}$ Hydrophilic Coated Guidewire, Terumo Medical Corporation, Somerset, NJ, USA), the guidewire was advanced to the intrahepatic portion of the right portal vein through a $5 \mathrm{~F}$ Berenstein wire-braided catheter (AngioDynamics, Mini Stick MAX 0.018" Coaxial Microintroducer Kit, Latham, NY, USA). In case of chronic occlusion, using venous recanalization technique, attempts were made to follow the course of the main portal vein to the right branch of the intrahepatic portal vein [Figure 4a].

Subsequently, the right internal jugular vein was punctured with ultrasound guidance, and a 10-Fr TIPS sheath was placed (Rosch-Uchida Transjugular Liver Access Set, COOK Medical Bloomington, IN, USA). The TIPS cannula was advanced through the transjugular approach into the right intrahepatic vein, and direct puncture was made using the mesenteric access guidewire or an inflated balloon as a guide, preferably into the right portal vein. A 0.018 or 0.035 -inch angled guidewire was advanced into the portal vein and snared through the mesenteric approach using a 10 or $15 \mathrm{~mm}$ snare [Figure 4b] (Captivator ${ }^{\mathrm{TM}}$ II, Boston Scientific, Natick, MA, USA). The wire was pulled through the mesenteric approach and exchanged over a $260 \mathrm{~cm}$ 0.035 Amplatz super stiff wire (Amplatz Super Stiff ${ }^{\text {тм }}$ Guidewire, Boston Scientific, Natick, MA, USA).

During the TIPS procedure, additional manipulations were performed to resolve portal, mesenteric, or splenic veins clots, such as mechanical thrombectomy (5 patients), thrombolysis infusion (6 patients), and angioplasty (7 patients) depending on the age of the PVT. Mechanical thrombectomy was initially performed in cases of isolated acute PVT [Figure 5a] or PVT extending into the SMV and splenic veins, to clear the largest burden of clot and prevent pulmonary embolism after the TIPS stent
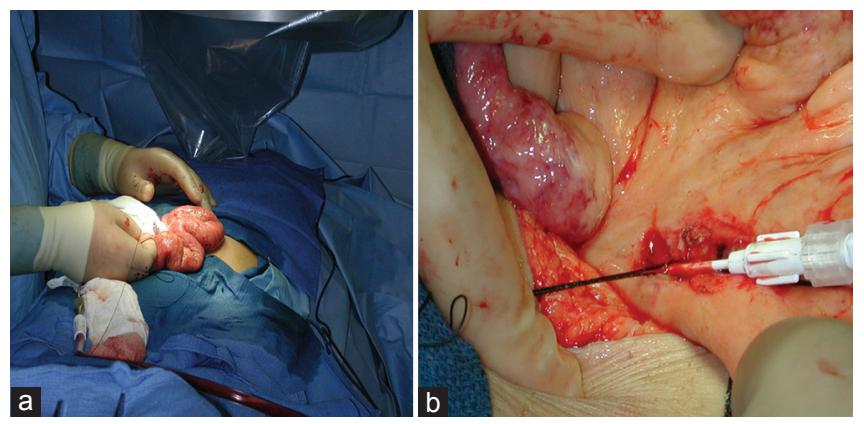

Figure 1: Access to peripheral mesenteric vein through a mini-laparotomy (a) and cannulation of the vein using micropuncture technique (b)

Table 1: Demographic and clinical characteristics of the patients before meso-transjugular intrahepatic portosystemic shunt

\begin{tabular}{lcll}
\hline Case number & Age (years) & Indications/symptoms & Inclusion criteria \\
\hline 1 & 32 & Ascites, severe abdominal pain & PVT, SMV, noncirrhotic liver, bowel ischemia \\
2 & 58 & Abdominal pain & PVT, SMV, noncirrhotic liver \\
3 & 52 & Ascites, severe abdominal pain & PVT, SMV, SVT \\
4 & 62 & Ascites, UGI bleed & PVT \\
5 & 34 & Ascites acute abdominal pain & PVT, SMV, SVT, bowel necrosis, noncirrhotic liver \\
6 & 61 & Ascites, PVT, failed TIPS & PVT, SMV, ESLD \\
7 & 30 & Recurrent ascites & PVT, alcoholic liver cirrhosis \\
9 & 61 & Acute PV, splenic vein thrombosis & PVT, SMV, SVT \\
\hline \hline
\end{tabular}

ESLD: End-stage liver disease, HCC: Hepatocellular carcinoma, PVT: Portal vein thrombosis, SMV: Superior mesenteric vein,

SVT: Splenic vein thrombosis, TIPS: Transjugular intrahepatic portosystemic shunt, UGI: Upper gastrointestinal 
is placed. Tissue plasminogen activator (tPA) was only used in the solution infused through the side port of the mechanical thrombectomy device used (Arrow-Trerotola ${ }^{\mathrm{TM}}$ device [Teleflex, Dublin, Ireland]) and consisted of a solution of $5 \mathrm{mg}$ of tPA diluted in $500 \mathrm{cc}$ of normal saline. In case of chronic PVT, the occluded vein was recanalized mainly by angioplasty with no mechanical or chemical thrombectomy/thrombolysis [Figure 5b]. In all manipulations, attempts were made to maintain the patency of the splenic vein to ensure adequate flow volume into the portal vein and shunt. Based on the authors' prior nonpublished experience, portal vein thrombolysis/thrombectomy where the burden of clot extends to the intrahepatic portal distribution, no placement of an outflow shunt ended with near immediate rethrombosis.

Viatorr stents, $2 \mathrm{~cm}$ of uncovered length and $8 \mathrm{~cm}$ of covered length (W. L. Gore, Newark, NJ, USA), were used in 7 cases, and uncovered Luminexx, $12 \mathrm{~mm}$ in diameter, $8 \mathrm{~cm}$ in length (Bard, Murray Hill, NJ), were used in 2 cases. Stents were deployed from the hepatic vein to the accessed portal vein and dilated to $12 \mathrm{~mm}$. In 8 cases, stents were extended to the main portal vein. In these patients, care was made not to cover the origin of the splenic vein to improve stent patency with blood inflow

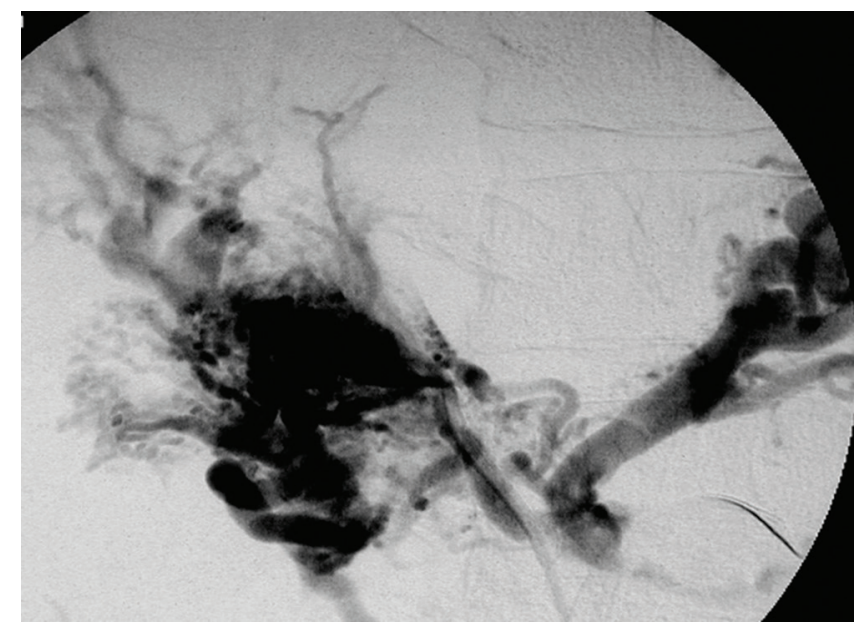

Figure 2: Initial mesenteric portogram after access to the peripheral mesenteric vein in a patient with chronic portal vein thrombosis and portal hypertension

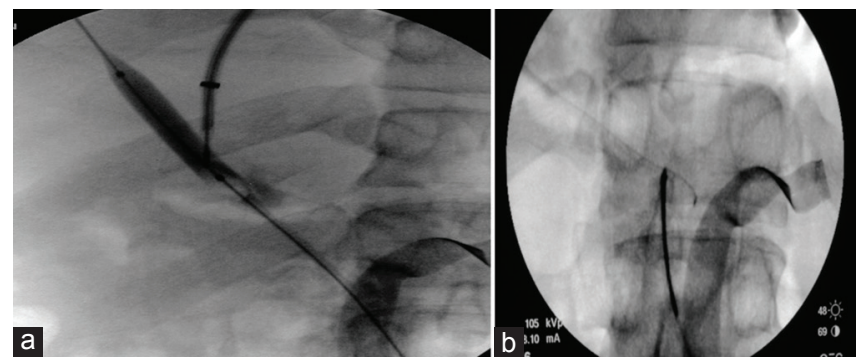

Figure 4: Access into the right portal vein using a preplaced balloon as a target (a) and snaring of the wire from the mesenteric approach (b) from the splenic vein. In one case where the splenic vein was completely and chronically thrombosed, the uncovered stent was extended to the SMV. Balloon angioplasty was also performed through the jugular approach to dilate the main portal, superior mesenteric, and splenic veins. Hemostasis was then obtained by the surgical team, and the mini-laparotomy was closed. A completion angiogram and portosystemic pressure measurements were performed in all patients to confirm good patency of the shunt [Figures 6 and 7].

Patients were followed up by Doppler Ultrasonography after MTIPS procedures, and TIPS revision was performed when restenosis was suspected.

\section{Results}

All nine patients had technically successful procedures as defined by the reduction of portosystemic gradient to normal values and TIPS patency. Doppler ultrasound was performed within the first 2 weeks after MTIPS to document shunt patency.

Procedure time ranged from 2 to $4 \mathrm{~h}$ with an average of $2 \mathrm{~h}$ and $36 \mathrm{~min}$. At the end of the procedure, one patient experienced a blood pressure drop from an initial systolic value of $120 \mathrm{~mm} \mathrm{Hg}$ to $80 \mathrm{~mm} \mathrm{Hg}$. Although no source of bleeding was noted, the patient was transfused with red blood cells and fresh frozen plasma after which blood pressure normalized. No issues with wound healing or ascetic leak occurred after laparotomy in all patients.

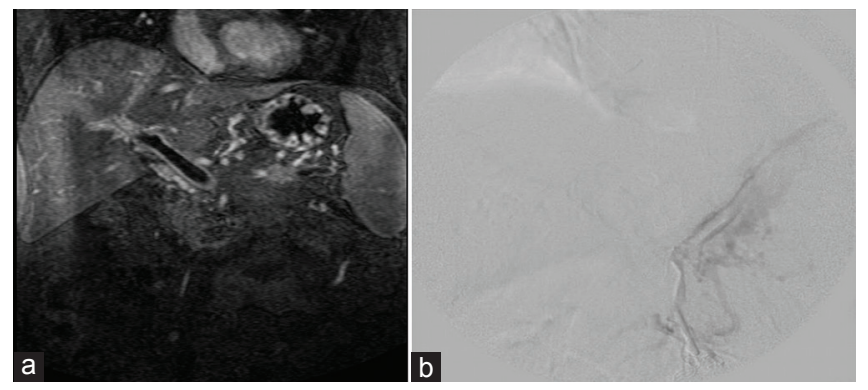

Figure 3: Initial magnetic resonance venography in a patient with acute portal vein thrombosis (a) and initial venogram on the same patient (b). Note, the large thrombus occupying the lumen of the main portal vein on the magnetic resonance venography and markedly decreased portal venous flow on the venogram with minimal collaterals

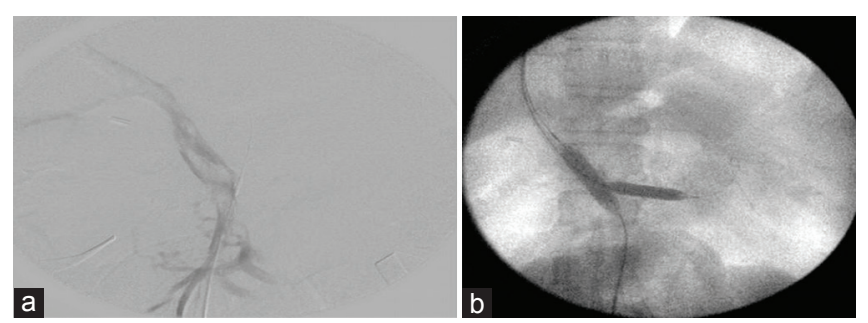

Figure 5: Mechanical thrombectomy using the Arrow Trerotola device (a) in a patient with acute portal vein thrombosis followed with "kissing angioplasties" (b) 


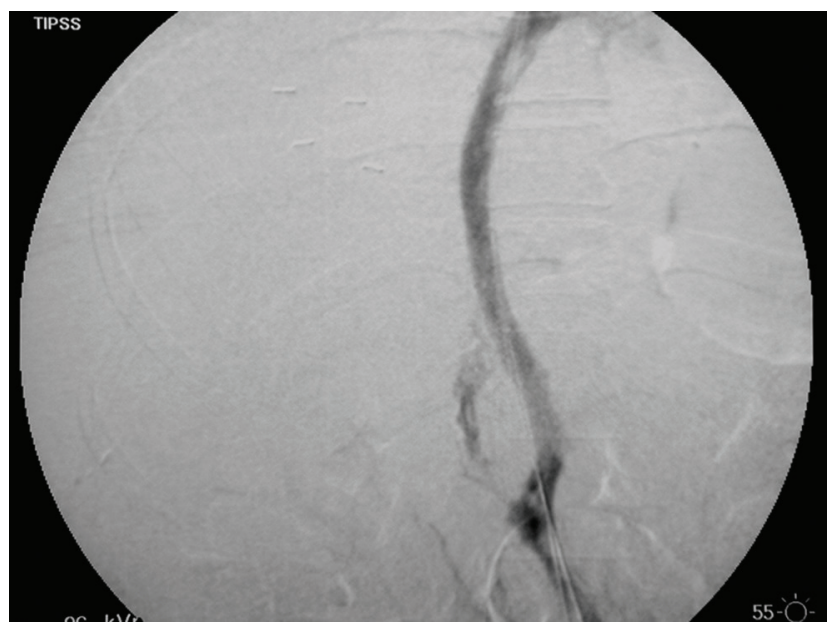

Figure 6: Final venogram post transjugular intrahepatic portosystemic shunt placement, note the resolution of the collaterals

Patients were followed up for a mean time of 13.3 months (range: 8 days to 3 years). At the time this manuscript was written, all patients were contacted by one of the authors and all found to be asymptomatic. Stent or venous rethrombosis was seen in all cases during initial 1 week postprocedure. In 2 patients, complete thrombosis of the stent was noted necessitating mechanical thrombectomy and angioplasty. Three patients had complete thrombosis of the splenic vein and 4 patients developed thrombosis of the main portal vein, all treated with clot aspiration and angioplasty. Six patients had follow-ups for at least 6 months; they had on average two TIPS revisions in this period. Following revision, they had normal flow and velocities through the TIPS [Table 2].

All patients are still alive and asymptomatic at the current period. One patient had complete rethrombosis of the TIPS but is still asymptomatic. His initial indication was bowel necrosis associated with acute massive PVT. It was felt that the procedure has decreased bowel congestion and improved viability in the postoperative phase. Even though his shunt thrombosed on the long run, it was felt that the procedure has given him enough time to develop collaterals.

\section{Discussion}

The simultaneous transhepatic approach has been described for treatment of PVT. ${ }^{[5,6]}$ However, to the best of our knowledge, the indication of mini-laparotomy-assisted TIPS in PVT has not been reported in a series. Our series shows that this technique restored portal and mesenteric venous outflow decreasing the degree of bowel congestion and therefore improving PVT-associated symptoms. Initial patency of the shunt was an issue due to extensive mesenteric venous thrombosis and resulting limited blood inflow in the TIPS shunt necessitating close monitoring and repeated interventions. Care was made to recanalize the splenic vein when possible as a supplemental inflow source.

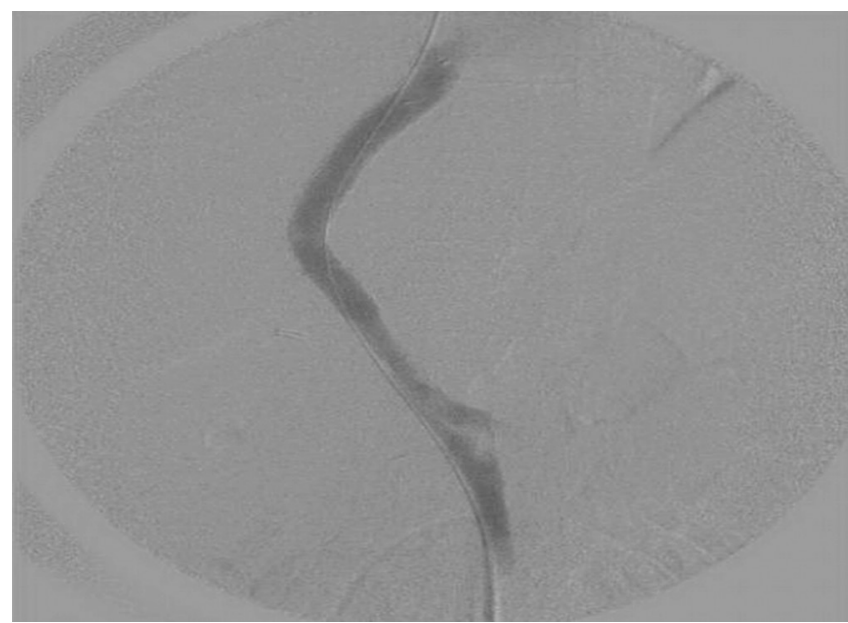

Figure 7: Final venogram postshunt placement

A recent large series comparing TIPS versus minilaparotomy-assisted transmesenteric-TIPS (MAT-TIPS) has shown a higher complication in MAT-TIPS with same shunt patency. However, these cases were not reported to have PVT, but rather normal patency of the portal vein was seen before procedures. ${ }^{[7]}$

Although PVT is uncommon, it can threaten the patient's life given the morbidity and mortality associated with its complications. To date, treatment of PVT and its complications includes endoscopic sclerotherapy, splenectomy, central splenorenal shunt with splenectomy, and selective splenorenal shunts. ${ }^{[1]}$ Nevertheless, these remain controversial with unsatisfactory results. As an alternative, percutaneous procedures may be performed to improve the clinical symptoms of PVT. They also proved to be effective in dissolving the thrombus ${ }^{[8]}$ through pharmacologic or mechanical thrombolysis, whether alone or associated with TIPS. ${ }^{[9-12]}$

TIPS procedure is performed to place a shunt between the portal and hepatic veins. It was first described in 1988 and proposed for the treatment of different indications in liver diseases, such as variceal bleeding in cirrhotic patients, refractory ascites, Budd-Chiari syndrome, ectopic portal hypertensive bleeding, portal thrombosis, whether acute or chronic. ${ }^{[1]}$

In this sense, Walser et al. described a series of 20 patients with symptomatic PVT. ${ }^{[13]}$ Of these, 12 patients had successful TIPS placement, resulting thus in a success rate of $60 \%$. Nonetheless, adjunctive hepatosplenic arterial embolization was required in 2 of these 12 patients to decrease flow into the portal system. ${ }^{[13]}$ Similarly, Stein and Link reported a technical success rate of $86 \%$ for portal vein reconstruction performed in 21 patients with symptomatic chronic spleno-mesenteric PVT. Of these 21 patients, 5 underwent primarily TIPS procedures and 16 transhepatic reconstructions of the portal vein, of which 7 were converted to TIPS. ${ }^{[12]}$ In 2004, Bilbao et al. 
Table 2: Follow-up of the patients

\begin{tabular}{|c|c|c|c|c|}
\hline $\begin{array}{l}\text { Case } \\
\text { number }\end{array}$ & Follow-up post-meso-TIPS & Follow-up duration & Angioplasty/stent post-meso-TIPS & Final follow-up \\
\hline \multirow[t]{13}{*}{1} & $\begin{array}{l}\text { Days } 3,4,5,6,8,911,12, \\
14,1528,41\end{array}$ & 6 months & Day 3 & $\begin{array}{l}\text { D1: Thrombosis; R1: Mechanical } \\
\text { thrombectomy }\end{array}$ \\
\hline & Months 2, 4, 5, 6 & & & D2: Decreased flow \\
\hline & & & & $\begin{array}{l}\text { D3: Questionable flow; } \\
\text { R2: Mechanical thrombectomy } \\
\text { and stent placement }\end{array}$ \\
\hline & & & & D4: Decreased flow \\
\hline & & & & D5: Normal flow \\
\hline & & & & D6: Decreased flow \\
\hline & & & & D7: Decreased flow \\
\hline & & & & D8: Improved flow \\
\hline & & & & D9: Stenosis \\
\hline & & & & $\begin{array}{l}\text { D10: Normal flow; R3: Successful } \\
\text { Doppler }\end{array}$ \\
\hline & & & & $\begin{array}{l}\text { D11: Normal flow; R4: Not } \\
\text { successful Doppler }\end{array}$ \\
\hline & & & & D12: Normal flow; R5: Stent tPA \\
\hline & & & & D13: Normal flow \\
\hline \multirow[t]{3}{*}{2} & Days 2, 4, 10, 20 & 9 months & Month 5 & TIPS check: No gradient and \\
\hline & Months 3, 4, 5, 6, 9 & & & repositioning of stent \\
\hline & & & & D: Patent \\
\hline \multirow[t]{11}{*}{3} & Days 6, 40 & 2 years & Days $3,8,9,13,17,24$ & D1: Patent \\
\hline & Months $3,4,6,7,8,12,13$, & & & D2: Decreased flow; R1: Patent \\
\hline & $14,16,17,19,20,24$ & & & $\begin{array}{l}\text { D3: No flow; R2: Successful by } \\
\text { Doppler }\end{array}$ \\
\hline & & & & $\begin{array}{l}\text { MRA: Normal; R3: Successful } \\
\text { MRA }\end{array}$ \\
\hline & & & & D4: Stenosis \\
\hline & & & & MRA: Stenosis \\
\hline & & & & $\begin{array}{l}\text { D5: Stenosis; R4: Successful } \\
\text { Doppler }\end{array}$ \\
\hline & & & & $\begin{array}{l}\text { D6: Occlusion; R5: Successful } \\
\text { Doppler }\end{array}$ \\
\hline & & & & $\begin{array}{l}\text { D7: Occlusion; R6: Mechanical } \\
\text { stent angioplasty }\end{array}$ \\
\hline & & & & R7: Successful Doppler \\
\hline & & & & R8: Successful Doppler \\
\hline 4 & Day 8 & 8 days & - & D: Normal flow \\
\hline \multirow[t]{5}{*}{5} & Days $10,12,20,23$ & 1 year & Month 3 & D1: Decreased velocity but patent \\
\hline & Months 2, 3, 6 & & & D2: Patent \\
\hline & Year 1 & & & $\begin{array}{l}\text { TIPS check: Repositioning } \\
\text { ( } 3 \text { months) }\end{array}$ \\
\hline & & & & TIPS check: Normal (8 months) \\
\hline & & & & TIPS check: Normal (13 months) \\
\hline \multirow[t]{2}{*}{6} & Day 15 & 2 years & Month 7 & D1: Patent \\
\hline & Months: $6,7,25,28$ & & & $\begin{array}{l}\text { D2: Some stenosis; } \\
\text { R1: Angioplasty }\end{array}$ \\
\hline \multirow[t]{2}{*}{7} & Day 4 & 3 months & - & D: Patent \\
\hline & Month 3 & & & \\
\hline
\end{tabular}


Table 2: Contd...

\begin{tabular}{|c|c|c|c|c|}
\hline $\begin{array}{l}\text { Case } \\
\text { number }\end{array}$ & Follow-up post-meso-TIPS & Follow-up duration & Angioplasty/stent post-meso-TIPS & Final follow-up \\
\hline \multirow[t]{15}{*}{8} & Days 3,11 & 3 years & Months 2, 3 & D1: Stenosis \\
\hline & Months $2,3,4,5,6,8,10$, & & & D2: Normal flow \\
\hline & $14,19,25,31,36$ & & & D3: Normal flow \\
\hline & & & & $\begin{array}{l}\text { D4: Questionable thrombosis; } \\
\text { R1: Stent placement }\end{array}$ \\
\hline & & & & D5: No flow; R2: Stent \\
\hline & & & & D6: Normal flow \\
\hline & & & & D7: Normal flow \\
\hline & & & & D8: Questionable thrombosis \\
\hline & & & & D9: Mild stenosis \\
\hline & & & & D10: No change \\
\hline & & & & D11: Normal flow \\
\hline & & & & D12: Normal flow \\
\hline & & & & D13: Normal flow \\
\hline & & & & D17: Normal flow \\
\hline & & & & D18: Decreased flow \\
\hline \multirow[t]{3}{*}{9} & Days $3,4,5,6,12,20$ & 3 weeks & Day 4 & $\begin{array}{l}\text { D1: Thrombosis then } \\
\text { thrombolysis }\end{array}$ \\
\hline & & & & D2: Patent \\
\hline & & & & D3: Patent \\
\hline
\end{tabular}

D: Doppler, MRA: Magnetic resonance angiography, R: Revision, tPA: Tissue plasminogen activator

described TIPS as an alternative therapy for 6 noncirrhotic patients with chronic PVT who had successful portal vein reconstructions followed by TIPS placements. ${ }^{[1]}$ Of these 6 patients, one died because of the progression of a tumoral occlusion. ${ }^{[1]}$ More recently in 2006, Van Ha et al. had a technical success rate of $75 \%$ in 15 cirrhotic patients with PVT who underwent TIPS procedure. ${ }^{[14]}$

Contrary to the series described above, the technical success rate was $100 \%$ in providing initial outflow to the portomesenteric venous system. Despite the fact that one patient ended developing nonsalvageable shunt occlusion, he benefited from initial drop in portal venous pressure which had caused his bowel necrosis and ended developing enough collaterals to keep him asymptomatic. Importantly, this series results are similar to those obtained following TIPS in patients without associated portal thrombosis. ${ }^{[15,16]}$ Consequently, outcomes of the MTIPS approach are satisfactory; all patients are still alive and asymptomatic at the current period.

Our study is limited by its small sample size. Unfortunately, the team of operators eventually got separated by transfer to other institutions, and the procedure was not performed by other individuals on both sides. To conclude, our results show that the MTIPS is effective for the relief of portal hypertension secondary to PVT. This may represent a good therapeutic option for these patients who are otherwise difficult to manage. A single case report had described a similar technique to ours in a previously published single-patient case report. ${ }^{[17]}$

\section{Conclusion}

Subsequent to the initial presentation of our series at the Society of Interventional Radiology annual scientific meeting in 2008 (Washington, D.C.), a single two-case report has been submitted. ${ }^{[18]}$ However, when considering the length of follow-up, the number of cases and technical aspects, and in particular the fact that all patients are still alive, as far as known to the authors, our brief report represents one of a kind series in the technique we describe herein.

\section{Acknowledgments}

We thank all patients who participated in the study and endured multiple phone calls and follow-ups.

Financial support and sponsorship

Nil.

\section{Conflicts of interest}

There are no conflicts of interest.

\section{References}

1. Bilbao JI, Elorz M, Vivas I, Martínez-Cuesta A, Bastarrika G, Benito A. Transjugular intrahepatic portosystemic shunt (TIPS) in the treatment of venous symptomatic chronic portal thrombosis in non-cirrhotic patients. Cardiovasc Intervent Radiol 2004;27:474-80.

2. Orfanidis NT. Portal Vein Thrombosis. Merck Manual. Professional Version. Available from: http://www. merckmanuals.com/professional/hepatic-and-biliary-disorders/ 
vascular-disorders-of-the-liver/portal-vein-thrombosis. [Last accessed on 2016 Mar 15].

3. Sanyal AJ. Epidemiology and Pathogenesis of Portal Vein Thrombosis in Adults. Literature Review Current Through; February, 2016. Available from: http://www.uptodate. com/contents/epidemiology-and-pathogenesis-of-portalvein-thrombosis-in-adults. [Last updated on 2015 Jun 25; Last accessed on 2016 Mar 15].

4. Hidajat N, Stobbe H, Griesshaber V, Felix R, Schroder RJ. Imaging and radiological interventions of portal vein thrombosis. Acta Radiol 2005;46:336-43.

5. Carnevale FC, Santos AC, Seda-Neto J, Zurstrassen CE, Moreira AM, Carone E, et al. Portal vein obstruction after liver transplantation in children treated by simultaneous minilaparotomy and transhepatic approaches: Initial experience. Pediatr Transplant 2011;15:47-52.

6. Nosaka S, Isobe Y, Kasahara M, Miyazaki O, Sakamoto S, Uchida $\mathrm{H}$, et al. Recanalization of post-transplant late-onset long segmental portal vein thrombosis with bidirectional transhepatic and transmesenteric approach. Pediatr Transplant 2013;17:E71-5.

7. Jalaeian $\mathrm{H}$, Talaie $\mathrm{R}$, D'Souza $\mathrm{D}$, Taleb $\mathrm{S}$, Noorbaloochi S, Flanagan S, et al. Minilaparotomy-assisted transmesenteric-transjugular intrahepatic portosystemic shunt: Comparison with conventional transjugular approach. Cardiovasc Intervent Radiol 2016;39:1413-9.

8. Okuda K, Ohnishi K, Kimura K, Matsutani S, Sumida M, Goto N, et al. Incidence of portal vein thrombosis in liver cirrhosis. An angiographic study in 708 patients. Gastroenterology 1985;89:279-86.

9. Bizollon T, Bissuel F, Detry L, Trepo C. Fibrinolytic therapy for portal vein thrombosis. Lancet 1991;337:1416.

10. Bilbao JI, Rodriguez-Cabello J, Longo J, Zornoza G,
Páramo J, Lecumberri FJ. Portal thrombosis: Percutaneous transhepatic treatment with urokinase - A case report. Gastrointest Radiol 1989;14:326-8.

11. Poplausky MR, Kaufman JA, Geller SC, Waltman AC Mesenteric venous thrombosis treated with urokinase via the superior mesenteric artery. Gastroenterology 1996;110:1633-5.

12. Stein M, Link DP. Symptomatic spleno-mesenteric-portal venous thrombosis: Recanalization and reconstruction with endovascular stents. J Vasc Interv Radiol 1999;10:363-71.

13. Walser EM, NcNees SW, DeLa Pena O, Crow WN, Morgan RA, Soloway R, et al. Portal venous thrombosis: Percutaneous therapy and outcome. J Vasc Interv Radiol 1998;9:119-27.

14. Van Ha TG, Hodge J, Funaki B, Lorenz J, Rosenblum J, Straus $\mathrm{C}$, et al. Transjugular intrahepatic portosystemic shunt placement in patients with cirrhosis and concomitant portal vein thrombosis. Cardiovasc Intervent Radiol 2006;29:785-90.

15. Bilbao JI, Longo JM, Rousseau H, de Villa V, Mansilla F, Alvarez-Cienfuegos J, et al. Transjugular intrahepatic portocaval shunt after thrombus disruption in partially thrombosed portal veins. Cardiovasc Intervent Radiol 1994;17:106-9.

16. Haskal ZJ. Treatment of acute mesenteric venous thrombosis with transjugular intramesenteric urokinase infusion: Invited commentaries. J Vasc Interv Radiol 1995;6:224-6.

17. Matsui O, Yoshikawa J, Kadoya M, Gabata T, Takashima T, Urabe $\mathrm{T}$, et al. Transjugular intrahepatic portosystemic shunt after previous recanalization of a chronically thrombosed portal vein via a transmesenteric approach. Cardiovasc Intervent Radiol 1996;19:352-5.

18. Sabri SS, Caldwell SH, Kumer SC, Schmitt TM, Maluf DG, Angle JF, et al. Combined transmesenteric and transhepatic recanalization of chronic portal and mesenteric vein occlusion to treat bleeding duodenal varices. J Vasc Interv Radiol 2014;25:1295-9. 